\title{
COMMENT
}

\section{Crab larval-release rhythms}

\author{
John D. Palmer* \\ Department of Biology, University of Massachusetts, Amherst, Massachusetts 01003, USA
}

A recent paper in Marine Biology by M. Saigusa \& O. Kawagoye entitled 'Circatidal rhythm of an intertidal crab, Hemigrapsus sanguineus: synchrony with unequal tide height and involvement of a lightresponse mechanism' (1997; Mar Biol 129:87-96) begins with a serious misstatement. After giving 2 examples of rhythms that are controlled by an endogenous clock, they go on to say on p 87 ,

But other patterns, e.g., locomotor activity of fiddler crabs, Uca spp...., that of the shore crab Carcinus maenas... and swimming activity of the fish Lipophrys pholis..., are, if anything, caused by a direct response of the animals to cyclical fluctuations in physical factors associated with the tidal cycle

The same claim, worded differently, is made on the next page-clearly these authors meant what they said: they think the rhythms of these animals are not controlled by an internal clock.

It is difficult to imagine how such a misunderstanding could arise: fiddler crabs and Carcinus are the classic organisms used in marine chronobiology studies. The first description of a clock-controlled tidal rhythm was done on a fiddler crab (Bennett et al. 1957) and the animal has continued to be studied to the present day. Scores of papers on the rhythmicity of this crab, emanating from several labs, have been published (see the 34 yr summary of this work by Palmer 1991). The first study of the internal-clock control of Carcinus maenas rhythms was performed in 1958 (Naylor), and there are at least 50 more papers that have appeared since then from Naylor's lab and several others. The first study of the tidal rhythm of the fish Lipophry pholis was done in 1965 (Gibson), and recently a nice series of papers (culminating in 1991) on the animal's rhythms have been published by Northcott, Gibson \& Morgan; a review of the $L$. pholis rhythm, and the

•E-mail: ftodd@bio.umass.edu rhythmicity of other intertidal fishes, was published by Gibson (1992). There cannot be the slightest doubt in the minds of marine chronobiologists (other than Saigusa \& Kawagoye) that the tide-associated rhythms of these 3 intertidal animals (and a great many others, see Palmer 1995) are under the control of internal living clocks.

Further on in their paper, Saigusa \& Kawagoye state that their results 'suggests [that] a light-response mechanism [is] involved even in the circatidal rhythm of intertidal animals' (p 92-93). This assertion is repeated again on $\mathrm{p}$ 94: 'This indicates that the 24 -h LD cycle functions as the zeitgeber of the circatidal rhythm of Hemigrapsus sanguineus.' This claim creates a problem in my mind. Certainly (to give an extreme example) one would not expect that the attendance of church each Sunday morning would set the phase of our second-to-second heart-beat rhythm. It is equally illogical to accept a conclusion that the 24 -h day-night cycle would set the phase or entrain an overt 12.4-h organismic tidal rhythm. If it did, the rhythm would no longer match the tides; it would become $24 \mathrm{~h}$ in length and lose the survival value once offered by a rhythm.

Those 2 comments out of the way, I will turn directly to the rhythm itself. Larvae release in this species is a one-time event, i.e. each individual sheds all its larvae in one ca 6 -h interval. This type of behavior is referred to in chronobiological literature as a 'gated response', meaning it takes place only when a 'gate' is opened to allow the event. When a batch of crabs is collected and brought into the laboratory, they do not all release their offspring on the same day; instead, individuals release at different times over an interval of several days. And when the response of an entire population, maintained in either a light-dark cycle or constant dim illumination, is plotted it is seen that individual releases occur roughly $25 \mathrm{~h}$ later each day. Taking the data at face value, the most obvious interpretation of the population-as-a-whole display is that it is a circa- 
lunar-day rhythm, not a 'circatidal rhythm' (i.e. a cycle with an approximate 12.4 -h period) as the authors define it to be throughout the paper beginning with the title; and on $\mathrm{p} 90$ they state, '...the internal period controlling larval release activity in each female is not $25 \mathrm{~h}$, but $12.5 \mathrm{~h}$.'

When larval release is studied in constant conditions, if one took no notice of the scheduling of the tides back in the crabs' old habitat, the interpretation would be a daily rhythm that had assumed a circa period in the lab-the same explanation made for the fruit-fly-eclosion rhythm (which is also a gated response). But it is clearly more than that, and that is what makes the Saigusa \& Kawagoye paper so interesting. The release is roughly synchronized with the times of high tide, even when the crabs are maintained in light-dark conditions. Furthermore, if the light-dark cycle is advanced or delayed by $6 \mathrm{~h}$, the release rhythm is advanced roughly $6 \mathrm{~h}$, or delayed about $3 \mathrm{~h}$, respectively. The authors state that ' $\mathrm{t}$ ] he 24 -h light-dark cycle definitely caused a phase-shift of the circatidal rhythm...' (emphasis mine).

Ignoring, for the moment, that there is no evidence that the authors are dealing with a circatidal rhythm, and that light-dark cycles do not entrain or phase shift tide-associated rhythms, how do we explain the phase changes produced by the experimental light-dark cycles? Here, in my opinion, the authors got it right, but came at their speculation in an unnecessarily abstruse way. Years ago, Colin Pittendrigh, via intellectual conjecture, proposed a hypothetical scheme that envisioned a 2-oscillator system, each based on a $24 \mathrm{~h}$ period, that could explain phase shifts in circadian rhythms (Pittendrigh 1965). Saigusa \& Kawagoye made one alteration in the Pittendrigh supposition in that one oscillator (named B) has a period of $12.4 \mathrm{~h}$, while the other retains the postulated $24 \mathrm{~h}$ period (named A). The B oscillator is responsible for larval release, and the $A$ oscillator, presumably coupled to the $B$ clock, responds to light-dark cycles. With the caveat that the 12.4 -h value is speculative, I go along with this hypothesis.
The authors could have made a much stronger case for this idea by searching the literature a bit more. There are 2 crabs whose rhythmic displays are actually known to be produced via the coupling of tide-associated and daily clocks. The locomotor rhythms of Carcinus maenas (Naylor 1958) and Sesarma reticulatum (Palmer 1967, 1990) are now classic examples.

One last comment. Saigusa \& Kawagoye seemed mildly concerned by their finding that the phase advance they report was larger than the delay. But actually this result fits in nicely with what is known about the differing phase responsiveness of circadian rhythms to light-dark cycles: the phase-response curve that describes these changes is almost always asymmetrical, meaning advance and delay amounts differ. Thus, what would have been more unusual for the authors to have found are identical phase advances and delays to the same zeitgeber.

\section{LITERATURE CITED}

Bennett MF, Shriner J, Brown RA (1957) Persistent tidal cycles of spontaneous motor activity in the fiddler crab, Uca pugnax. Biol Bull Mar Biol Lab, Woods Hole 112:267-275

Gibson RN (1992) Tidally synchronized behaviour in marine fishes. In: Ali MA (ed) Rhythms in fishes. Plenum Press, London, $\mathrm{p}$ 63-82

Naylor E (1958) Tidal and diurnal rhythms of locomotory activity in Carcinus maenas. J Exp Biol 35:602-610

Northcott SJ, Gibson RN, Morgan E (1991) Phase responsiveness of the activity rhythm of Lipophrys pholis to a hydrostatic pressure pulse. J Exp Mar Biol Ecol 148:47-57

Palmer JD (1967) Daily and tidal components in the persistent rhythmic activity of the crab, Sesarma. Nature 215:64-66

Palmer JD (1990) Comparative studies of tidal rhythms. X. A dissection of the persistent activity rhythms of the crab, Sesarma. Mar Behav Physiol 17:177-187

Palmer JD (1991) Contributions made to chronobiology by studies of fiddler crab rhythms. Chronobiol Int 8:110-130

Palmer JD (1995) The biological rhythms and clocks of intertidal animals. Oxford University Press, New York

Pittendrigh CS (1965) On the mechanism of the entrainment of a circadian rhythm by light cycles. In: Aschoff J (ed) Circadian clocks. North-Holland Publ, Amsterdam, p $277-300$ 